\title{
글
}

RESEARCH AND EDUCATION

\section{Antimicrobial activity of conventional and plant-extract disinfectant solutions on microbial biofilms on a maxillofacial polymer surface}

\author{
Aimée Maria Guiotti, DDS, MSc, PhD, ${ }^{a}$ Bruno Guandalini Cunha, DDS, ${ }^{\mathrm{b}}$ Marcela Borghi Paulini, DDS, ${ }^{\mathrm{c}}$ \\ Marcelo Coelho Goiato, DDS, MSc, PhD, ${ }^{d}$ Daniela Micheline dos Santos, DDS, MSc, PhD, \\ Cristiane Duque, DDS, MSc, PhD, ${ }^{f}$ Karina Sampaio Caiaffa, DDS, MSc, ${ }^{g}$ Daniela Atili Brandini, DDS, MSc, $\mathrm{PhD}^{\text {h }}$ \\ Derly Tescaro Narciso de Oliveira, DDS, MSc, Natália Seron Brizzotti, ${ }^{j}$ and \\ Margarete Teresa Gottardo de Almeida, MSc, PhD ${ }^{\mathrm{k}}$
}

\begin{abstract}
Statement of problem. Dentists often note problems with infection in patients with maxillofacial prostheses. Conventional disinfection protocols are not always effective and may alter the properties of the polymer used in the prosthesis. Thus, the search for improved disinfection methods is important.
\end{abstract}

Purpose. The purpose of this in vitro study was to evaluate and compare the antimicrobial activity of conventional disinfectant solutions (water and neutral soap and 4\% chlorhexidine) and plant extracts (Cymbopogon nardus and Hydrastis canadensis) on specimens of maxillofacial silicone contaminated with Candida albicans and Staphylococcus aureus biofilms.

Material and methods. Seventy-two silicone (MDX4-4210) specimens were fabricated $(5 \times 2 \mathrm{~mm})$ and sterilized. Thirty-six were contaminated with $C$ albicans $\left(10^{6}\right.$ cells $\left./ \mathrm{mL}\right)$ and 36 with $S$ aureus $\left(10^{8}\right.$ cells $\left./ \mathrm{mL}\right)$ to evaluate the antimicrobial activity of the cleaning protocols. After incubation $\left(37^{\circ} \mathrm{C} / 72\right.$ hours), the specimens were divided into 5 groups: not disinfected (positive control), soaking in saline solution for 10 minutes, soaking in $4 \%$ chlorhexidine for 10 minutes, soaking in $C$ nardus for 10 minutes, soaking in $H$ canadensis for 10 minutes, and washing by hand with water and neutral soap for 30 seconds. The viability of cells was evaluated by XTT (2,3-bis-(2-methoxy-4-nitro-5sulfophenyl)-2H-tetrazolium-5-carboxanilide) assay and by scanning electron microscope analysis. The results were analyzed by ANOVA and the Tukey HSD test $(\alpha=.05)$.

Results. All disinfection solutions provided a statistically significant reduction in biofilm viability compared with the control group for both microorganisms $(P<.05)$. Washing with water and neutral soap was significantly more effective in reducing biofilm viability than immersion in the disinfection solutions, with persistence of viable microorganisms between $1.05 \%$ for $C$ albicans and $0.62 \%$ for $S$ aureus after this cleaning protocol. Photomicrographs revealed that $4 \%$ chlorhexidine altered the surface of the polymer.

Conclusions. Within the limitations of this in vitro study, it was concluded that the cleaning protocols with different disinfectant solutions produced a significant reduction in the viability of $C$ albicans and $S$ aureus biofilms on the silicone polymer. Washing with water and neutral soap was the most effective protocol against both microorganisms. (J Prosthet Dent 2016;116:136-143)

\footnotetext{
${ }^{a}$ Assistant Professor, Department of Dental Materials and Prosthodontics, Araçatuba Dental School, São Paulo State University (UNESP), São Paulo, Brazil. ${ }^{b}$ Graduate student, Department of Dental Materials and Prosthodontics, Araçatuba Dental School, São Paulo State University (UNESP), São Paulo, Brazil. ${ }^{c}$ Graduate student, Department of Dental Materials and Prosthodontics, Araçatuba Dental School, São Paulo State University (UNESP), São Paulo, Brazil.

${ }^{\mathrm{d}}$ Titular Professor, Department of Dental Materials and Prosthodontics, Araçatuba Dental School, São Paulo State University (UNESP), São Paulo, Brazil.

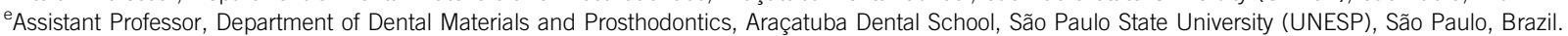
${ }^{f}$ Assistant Professor, Department of Pediatric and Public Health, Araçatuba Dental School, São Paulo State University (UNESP), Araçatuba, São Paulo, Brazil. gDoctoral student, Department of Pediatric and Public Health, Araçatuba Dental School, São Paulo State University (UNESP), São Paulo, Brazil.

${ }^{\text {h}}$ Assistant Professor, Department of Surgery and Integrated Clinic, Araçatuba Dental School, São Paulo State University (UNESP), São Paulo, Brazil. 'Doctoral student, Department of Dermatologic, Infectious and Parasitic Diseases, Medical School of São José do Rio Preto (FAMERP), São Paulo, Brazil. jBiologist, Department of Dermatologic, Infectious and Parasitic Diseases, Medical School of São José do Rio Preto (FAMERP), São Paulo, Brazil.

kProfessor, Department of Dermatologic, Infectious and Parasitic Diseases, Medical School of São José do Rio Preto (FAMERP), São Paulo, Brazil.
} 


\section{Clinical Implications}

Plant extracts are promising prophylactic and disinfectant agents against bacterial and fungal organisms, suggesting that these solutions might be useful as antimicrobial topical solutions for silicone elastomers.

Maxillofacial deformities are embarrassing and make patients feel self-conscious. These defects, whether congenital or caused by trauma or cancer surgery, traumatize the individuals and diminish them physically and psychologically., ${ }^{1,2}$ Plastic surgery, when the circumstances are favorable, is the treatment of choice. ${ }^{2}$ Indeed, autoplastic repair, or repair using in vivo tissue, is more desirable than alloplastic or artificial repair. However, there are patients with congenital or acquired defects for which restoration using prostheses is more appropriate. In fact, the rehabilitation of these patients using prosthetic restoration provides favorable results in terms of esthetics and personal well-being, making their reintegration into their social and family environment possible and acting as psychologic therapy by making them feel happier and more self-confident. ${ }^{3}-5$

Currently, the most common materials used to make facial prostheses are thermally activated acrylic resin and silicones. ${ }^{6-8}$ Silicone is the best material because of its flexibility, patient comfort, and texture, which is similar to human skin. ${ }^{9-11}$

Deficient hygiene of dental and maxillofacial prostheses contributes to the susceptibility of surrounding tissues to infections. ${ }^{12-16}$ Normal skin is rich in microorganisms, fungi, and bacteria, which naturally inhabit the skin surface. However, under conditions such as excessive heat and moisture, in patients with poorly controlled diabetes mellitus, or after prolonged administration of antibiotics, these microorganisms can cause endogenous infections and form biofilms. A biofilm is defined as a community of microorganisms adhering to a surface and surrounded by a complex matrix of extrapolymeric substances. ${ }^{17}$ Biofilms are composed of a set of different microorganisms that live together, in tissues and on prostheses, catheters, and other surfaces, forming a multicellular community. ${ }^{18}$ Thus, the natural tendency of microorganisms to live in communities creates immune protection against host defenses and the action of antimicrobial agents, thus favoring the establishment of pathogenic processes. ${ }^{17,19,20}$

Chemical disinfection using nonirritating disinfectant solutions ensures the health of tissues that come into contact with prostheses because, when properly cleaned, the risk of infection is minimized. ${ }^{13-16}$ Conventional cleaning protocols involve mechanical biofilm removal
Table 1. Names and manufacturers of disinfectant solutions

\begin{tabular}{ll}
\hline Material & \multicolumn{1}{c}{ Manufacturer } \\
\hline Saline solution & Tayayna Laboratory \\
\hline Neutral soap & Johnson \& Johnson Ltd \\
\hline $4 \%$ chlorhexidine & Specially prepared, Aphoticário \\
& Farmácia \\
\hline Plant extract Hydrastis canadensis & Specially prepared, Schraiber \\
(Family Ranunculaceae, North America) & Homeopatia-Schraibmann \\
& Laboratory Ltd \\
\hline Plant extract Cymbopogon nardus & Specially prepared, Pharmaspecial \\
(Family Poaceae, tropical Asia) & Espec Quim Farm Ltd \\
\hline
\end{tabular}

(with manual toothbrushing or washing by hand with water and neutral soap), ${ }^{21-25}$ effervescent solutions such as cleansing tablets, ${ }^{22-25}$ sodium hypochlorite $0.5 \%$ to $1 \%,{ }^{26-29}$ and chlorhexidine $2 \%$ to $4 \% \cdot{ }^{13,22-24,30-33}$ However, frequent exposure to these solutions may interfere with the properties of silicone. ${ }^{22-25,27-29,31,33,34}$ Thus, research is necessary to find alternative methods of disinfection using solutions that do not alter the silicone surface and that are harmless to individuals. ${ }^{35}$

Given the paucity of studies in dentistry on this issue, phytotherapy seems to be one possible option, as it is inexpensive and easy to use. ${ }^{35,36}$ Essential oils derived from aromatic and medicinal plants are potentially useful as antimicrobial agents, and their use as medicines has been widely recognized. ${ }^{37}$ An essential oil, commonly known as citronella (Cymbopogon nardus), extracted from a type of lemongrass, is widely used as an insect repellent. The main chemical components of this essential oil are antiseptics, geraniol, and citronellol, hence its extensive use in household disinfectants and soaps. ${ }^{38}$ Another candidate plant is hydrastis (Hydrastis canadensis), with its main chemical components being opianic acid, alkaloids, chlorogenic acid, berberine, hydrastine, and canadine. In medicine, this plant has been widely used for its astringent, antiinflammatory, antimicrobial, expectorant, and anthelmintic properties, among others. ${ }^{39,40}$ Thus, $C$ nardus and $H$ canadensis are considered to be plants that have antibacterial and antifungal potential, which may be useful in the control of infections in humans.

The purpose of this study was to evaluate the antimicrobial activity of plant extracts compared with conventional disinfectant solutions on specimens of medical grade silicone contaminated with Candida albicans and Staphylococcus aureus biofilms.

\section{MATERIAL AND METHODS}

This study examined the effectiveness of conventional and plant-extract solutions to disinfect elastomer specimens of the material used to manufacture maxillofacial prosthetics. Table 1 lists the names and manufacturers of the disinfectant solutions. 
Table 2. Distribution of specimens subjected to microbiologic analysis between fungal and bacterial groups

\begin{tabular}{llc}
\hline Group & $\begin{array}{c}\text { Disinfectant solution } \\
\text { (Subgroup), } \mathbf{n = 6}\end{array}$ & $\begin{array}{c}\text { Microbiological } \\
\text { analysis }\end{array}$ \\
\hline Staphylococcus aureus ( $\mathrm{n}=36)$ & Sterile & SEM \\
\hline & Water and neutral soap & $\mathrm{XTT}$ \\
\hline Candida albicans ( $\mathrm{n}=36)$ & $4 \%$ chlorhexidine \\
\hline & $4 \%$ chlorhexidine & SEM \\
\hline & Hydrastis canadensis & $\mathrm{XTT}$ \\
\hline & Cymbopogon nardus \\
\hline
\end{tabular}

SEM, scanning electron microscope; XTT, 2,3-bis-(2-methoxy-4-nitro-5-sulfophenyl)$2 \mathrm{H}$-tetrazolium-5-carboxanilide.

Seventy-two disk-shaped specimens (5 $\mathrm{mm}$ in diameter, $2 \mathrm{~mm}$ thick) of a maxillofacial silicone elastomer (MDX4-4210; Dow Corning Corp) were fabricated using a metallic matrix. The MDX4-4210 silicone elastomer was manually mixed in a ratio of 10:1 (base:catalyst), according to the manufacturer's instructions. It was prepared at room temperature $\left(23 \pm 2^{\circ} \mathrm{C}\right)$ and a relative humidity of $50 \% \pm 10 \%$. After the silicone had been prepared, it was placed into the matrix, and the surface was smoothed with a spatula at the edge of the matrix to a thickness of 2 $\mathrm{mm} .{ }^{35}$ Air bubbles in the mixture were eliminated by 30 minutes' incubation in a pressure pot (M500; EDG Equipment) at $140 \mathrm{kPa}{ }^{41}$

The matrix filled with silicone specimens was left in the mold, with the external surface exposed to the room environment for 3 days to complete the polymerization process. After this period, the specimens were removed from the mold with a fine-pointed instrument, and the excesses and irregularities of specimens were removed with thin, curved scissors. ${ }^{4,32}$ A uniform surface smoothness was maintained for cell attachment, but the surface was not finished or polished, simulating what is typically done in processing these prostheses, in which frequently only the edges are trimmed, ${ }^{42}$ and extrinsically stained before delivery. ${ }^{42-44}$

The specimens were sterilized with ethylene oxide and divided into 2 groups: 36 specimens were contaminated with $S$ aureus and 36 with $C$ albicans. In addition to the contaminated groups, a sterile group was used as a control (Table 2). The viability of cells was evaluated by XTT assay ${ }^{14-16,45,46}$ and by scanning electron microscopic (SEM) analysis. ${ }^{41,45}$

Two microorganism strains obtained from the American Type Culture Collection (ATCC) were evaluated: C albicans (ATCC 26790) and S aureus (ATCC 14458). These microbial strains were provided by the Instituto Oswaldo Cruz-FIOCRUZ. All strains were maintained frozen at $-70^{\circ} \mathrm{C}$ until the assay. Aliquots of $25 \mathrm{~mL}$ of each microorganism were spread in petri dishes containing Sabouraud dextrose agar and mannitol salt agar (Difco Laboratories Ltda) for $C$ albicans and $S$ aureus, respectively, and incubated at $37^{\circ} \mathrm{C}$ for 24 hours. After this, a loopful of each cultivated microorganism was individually subcultured in $5 \mathrm{~mL}$ of Sabouraud dextrose medium for $C$ albicans and in brain-heart infusion medium for $S$ aureus, which had been grown aerobically overnight at $37^{\circ} \mathrm{C}$ for 18 to 24 hours before assay. After this period, $200 \mu \mathrm{L}$ of each cultivated suspension was resuspended in a culture medium and spectrophotometrically standardized at an optical density (OD) of $520 \mathrm{~nm}$ to a final concentration of $1 \times 10^{6}$ cells $/ \mathrm{mL}$ for $C$ albicans $(\mathrm{OD}=0.3)$ and a final concentration of $1 \times 10^{8}$ cells/mL for $S$ aureus suspension $(\mathrm{OD}=0.5)$. The resulting suspensions were used for all further procedures.

$C$ albicans and $S$ aureus biofilms were developed on the silicone specimens' surface. Briefly, the silicone specimens were placed inside 2 presterilized 24-well microtiter plates, and aliquots of $2 \mu \mathrm{L}$ of the standardized cell suspensions were transferred into each well with $1000 \mu \mathrm{L}$ of Sabouraud and brain-heart infusion mediums for $C$ albicans and $S$ aureus, respectively. The microtiter plates were incubated for 72 hours at $37^{\circ} \mathrm{C}$ in an orbital shaker at $75 \mathrm{rpm}$ under aerobic conditions for biofilm formation on the surface of the material. After incubation, the wells were washed twice with phosphatebuffered saline (PBS) to remove nonadherent cells.

After biofilm formation, 36 specimens for each microorganism were divided into 5 subgroups $(n=6)$ : positive control and experimental groups. In the positive control group, the specimens were immersed in saline solution for 10 minutes. In the experimental groups, the specimens were disinfected by soaking for 10 minutes in $4 \%$ chlorhexidine, $H$ canadensis, and $C$ nardus, and 1 group was subjected to washing by hand with water and neutral soap for 30 seconds (Table 2). The effect of the disinfection protocols on biofilm viability was evaluated by the XTT reduction assay, and the specimens were analyzed by scanning electron microscopy (Model JSM 5410; JEOL).

The effect of the disinfection solutions on biofilm viability was evaluated by the XTT reduction assay, a quantitative analysis with 2,3-bis-(2-methoxy-4nitro-5-sulfophenyl)-2H-tetrazolium-5-carboxanilide to determine the formation of biofilm. The activity of the mitochondrial dehydrogenase reduces the XTT tetrazolium salt to formazan salt, resulting in a colorimetric change correlating with the cell viability. ${ }^{29}$

An XTT salt solution (Sigma-Aldrich) was prepared in ultrapure water at a final concentration of $1 \mathrm{mg} / \mathrm{mL}$, and menadione solution ( $0.4 \mathrm{mM}$ in acetone; Sigma-Aldrich) was prepared immediately before each assay. The disinfection solutions were added to each well of a microtiter plate containing 1 silicone specimen to be tested for 10 minutes. For the group subjected to washing with water and neutral soap, the specimens were removed from the microtiter plate, cleaned, and then replaced in the well. After this, all specimens were washed twice 
Table 3. Absorbance and cell viability Candida albicans and Staphylococcus aureus from positive control and experimental groups

\begin{tabular}{|c|c|c|c|c|}
\hline \multirow[b]{2}{*}{ Disinfectant } & \multicolumn{2}{|c|}{ C albicans } & \multicolumn{2}{|c|}{ S aureus } \\
\hline & Absorbance (OD) (Mean \pm SD) & Cell Viability (\%) & Absorbance (OD) (Mean \pm SD) & Cell Viability (\%) \\
\hline Positive control & $1.89 \pm 0.28$ & $100^{a}$ & $1.60 \pm 0.16$ & $100^{a}$ \\
\hline Hydrastis canadensis & $0.84 \pm 0.32$ & $44.44^{b . c}$ & $0.54 \pm 0.09$ & $33.75^{b}$ \\
\hline Cymbopogon nardus & $0.61 \pm 0.14$ & $32.27^{\mathrm{b}}$ & $0.12 \pm 0.06$ & $7.5^{c}$ \\
\hline 4\% chlorhexidine & $0.96 \pm 0.19$ & $50.79^{c}$ & $0.41 \pm 0.06$ & $25.62^{d}$ \\
\hline Water and neutral soap & $0.02 \pm 0.02$ & $1.05^{d}$ & $0.01 \pm 0.00$ & $0.62^{\mathrm{e}}$ \\
\hline
\end{tabular}

OD, optical density. Statistically significant differences between groups indicated by different superscript letters (within column), Tukey HSD test, $P<.05$.

with $2 \mathrm{~mL}$ PBS and transferred to new wells with a mixture of $1580 \mu \mathrm{L}$ PBS with $200 \mathrm{mM}$ glucose, $400 \mu \mathrm{L}$ $\mathrm{XTT}$, and $20 \mu \mathrm{L}$ menadione in each well. The plates were incubated for 3 hours in the dark at $37^{\circ} \mathrm{C}$. An aliquot of $1 \mathrm{~mL}$ of the solution of each well was transferred to a new 96-well microtiter plate, and measures were read by a microtiter plate reader (iMark Microplate Reader; Bio-Rad) at $492 \mathrm{~nm}$. All experiments were performed in triplicate on 3 independent occasions. The colorimetric change (absorbance values or OD) obtained was transcribed as percentages to facilitate the analysis of cell viability. The effect of the disinfection solutions on the metabolic activity of the biofilm was measured as the percentage of cell viability in relation to the XTT absorbance values (OD) of the control (100\% of viability). The data of the OD were converted into numeric data (\% of cell viability). The equation was: $\{\%$ of cell viability $=[O D$ (specimen test) $\times 100 \%] /[O D$ (control specimen)]\}.

For SEM evaluation, the specimens were sputtered with a thin gold layer using a sputter coater (E-1010; Hitachi). Subsequently, the surface of silicone specimens was observed with SEM (Model JSM 5410; JEOL). The accelerating voltage was $15 \mathrm{kV}$ and magnification was $\times 1000$.

The effect of the disinfection protocols on the metabolic activity of the biofilms was measured as the percentage of cell viability in relation to the XTT absorbance values of the control. Because the data satisfied the assumptions of normality and homogeneity (Kolmogorov-Smirnov test, $P>.05)$, parametric statistics were performed. The results were analyzed by ANOVA and the Tukey HSD test $(\alpha=.05)$ by SPSS v20.0 software (IBM).

\section{RESULTS}

Table 3 shows the results of the XTT assay of $C$ albicans and $S$ aureus biofilms in relation to the absorbance and percentage of cell viability with respect to different disinfection solutions. The mean absorbance obtained from the control groups of $C$ albicans was 1.88 and of $S$ aureus 1.60. All disinfection solutions showed statistically significant reduction in biofilm viability (absorbance) compared with the control group for both microorganisms $(P<.05)$.
The results demonstrated that washing with water and neutral soap was significantly $(P<.001)$ more effective in reducing biofilm viability than immersion in the disinfection solutions, with the persistence of viable microorganisms between $1.05 \%$ for C albicans and $0.62 \%$ for $S$ aureus after this cleaning protocol. A significant reduction in biofilm viability was also observed after immersion in $C$ nardus plant-extract solution, with the persistence of viable microorganisms between $32.27 \%$ for $C$ albicans $(P<.001)$ and $7.44 \%$ for $S$ aureus $(P<.001)$.

When disinfectant solutions were compared for $C$ albicans biofilm reduction, $C$ nardus was the most effective (32.27\% of cell viability), but with no difference among $H$ canadensis ( $44.44 \%$ of cell viability; $P>.05$ ). However, $C$ nardus was significantly different from $4 \%$ chlorhexidine $(50.79 \%$ of cell viability; $P<.05)$. For $S$ aureus biofilm, a significant reduction in biofilm viability was promoted by all disinfectant solutions, but with significant differences among them $(P<.05)$. The most effective solutions were $C$ nardus (7.44\% of cell viability) and $4 \%$ chlorhexidine $(25.62 \%$ of cell viability). $H$ canadensis was the solution that had the lowest effectiveness on the biofilm of $S$ aureus (33.75\% of cell viability).

Figures 1 and 2 show photomicrographs of the surface of the Silastic MDX 4-4210 silicone specimens contaminated with $C$ albicans and $S$ aureus and subjected to different disinfection protocols. For comparison, Figures $1 \mathrm{~B}$ and $2 \mathrm{~B}$ show the specimens' surfaces covered with a biofilm of $C$ albicans and $S$ aureus, respectively. Specimens disinfected with $H$ canadensis (Fig. 1D) and $C$ nardus (Fig. 1E) show fungi cells remained attached to the surface, even though more than $50 \%$ of the biofilm was inactivated, as was seen by the XTT assay (Table 3). The surface of the specimens contaminated with $S$ aureus and disinfected with $H$ canadensis (Fig. 2D) shows scattered bacterial cells. However, for C nardus, bacterial cells were absent (Fig. 2E), which is in accordance with the XTT assay (Table 3).

Washing with water and neutral soap removed the biofilms, leaving the silicone surface free of microorganisms (Fig. 1C, 2C), similar to the sterile groups (Fig. 1A, 2A). The surface of the specimens subjected to disinfection with $4 \%$ chlorhexidine presented a modified surface. 

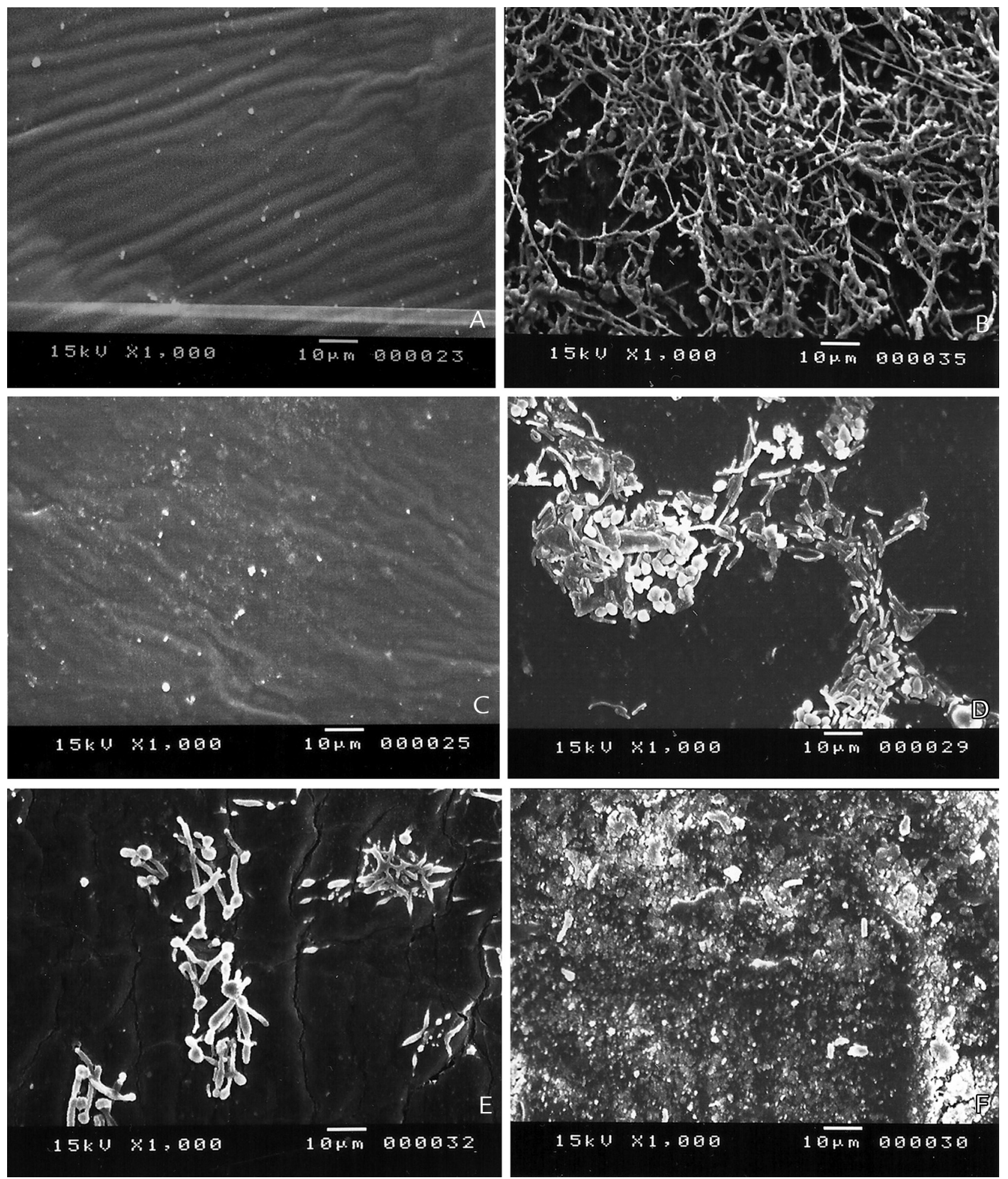

Figure 1. SEM analysis of silicone specimens (original magnification, $\times 1000$ ) A, Sterile silicone. B, Positive control for C albicans. C, Cleaned with water and neutral soap for $C$ albicans. D, Disinfected with $H$ canadensis for $C$ albicans. E, Disinfected with $C$ nardus for $C$ albicans. F, Disinfected with $4 \%$ chlorhexidine for $C$ albicans.

This fact is evident in photomicrographs with the formation of an impregnated layer (Fig. 1F) and the formation of cracks in the material's surface (Fig. 2F).

\section{DISCUSSION}

Proper routine cleaning of a prosthesis is required to prevent infection and maintain healthy supporting 

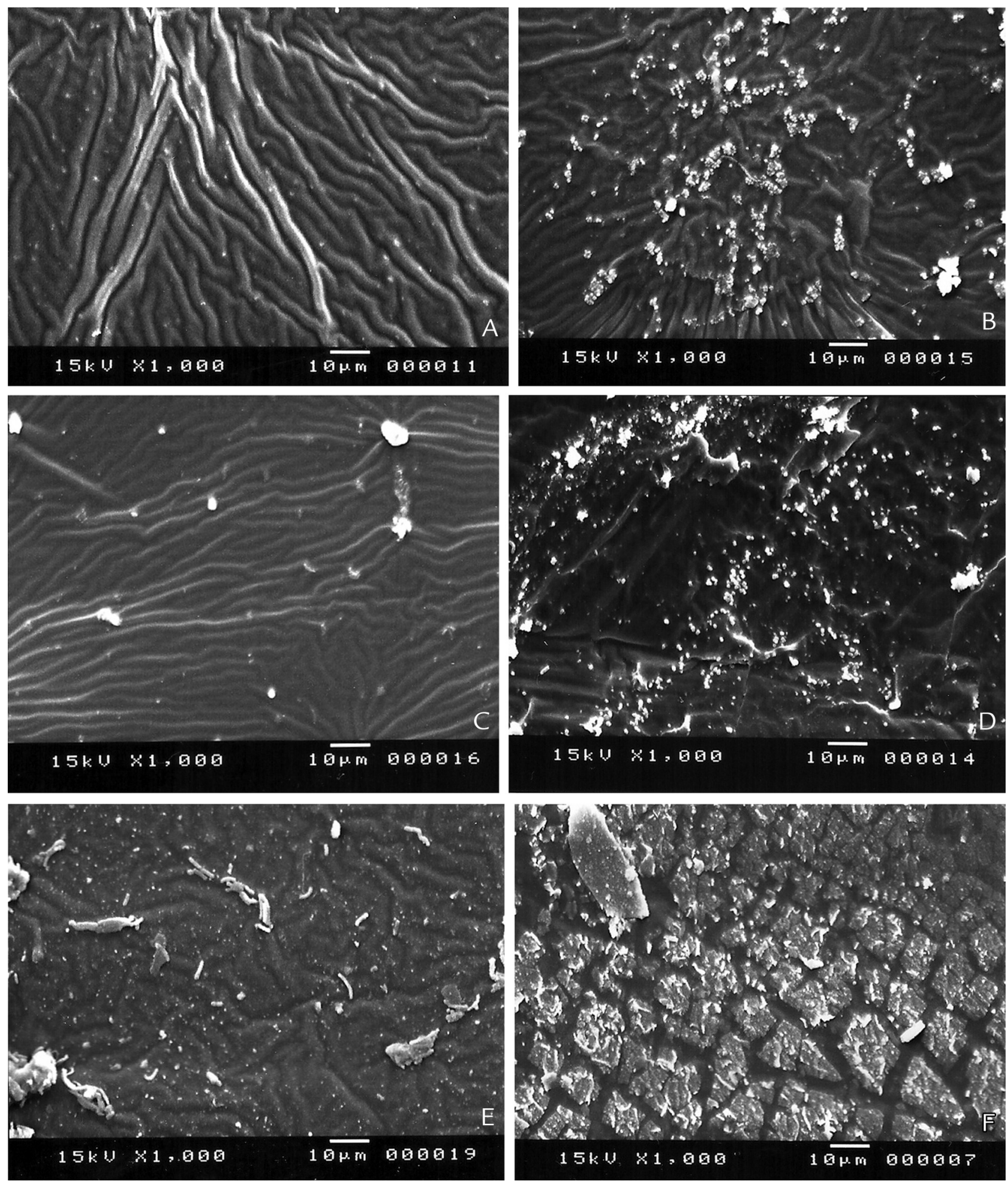

Figure 2. SEM of silicone specimens (original magnification, $\times 1000$ ) A, Sterile silicone. B, Positive control for $S$ aureus. C, Cleaned with water and neutral soap for $S$ aureus. D, Disinfected with $H$ canadensis for $S$ aureus. E, Disinfected with $C$ nardus for $S$ aureus. F, Disinfected with $4 \%$ chlorhexidine for $S$ aureus.

tissues. Therefore, this study investigated the effectiveness of disinfection solutions in deactivating $C$ albicans and $S$ aureus biofilms grown on a silicone polymer surface.
Mechanical biofilm removal is considered the most common and effective method of controlling biofilm development. ${ }^{14,21}$ From the results of the present in vitro investigation, a reduction of almost $100 \%$ in the viability 
of the $C$ albicans and $S$ aureus biofilms was observed after manual washing with water and neutral soap. This reduction was probably due to the mechanical action provided by the washing. Under these conditions, biofilm may be mechanically disrupted from the silicone surface. However, some authors have suggested that washing by hand, even when gently performed, induces detachment of the compounds incorporated into the elastomer matrix for the characterization of maxillofacial silicone prostheses. ${ }^{25,27}$ The hygiene of a maxillofacial prosthesis in silicone polymer is a delicate procedure that, if performed improperly, can accelerate the deterioration of the material. ${ }^{10,11,23-25,27-29,31}$

The $4 \%$ chlorhexidine solution was not an effective disinfectant against $C$ albicans, with persistence of viable microorganisms of approximately $50 \%$ after immersion for 10 minutes. In contrast, other studies have shown its effectiveness on Candida biofilm, but on dental prostheses (in acrylic resins specimens). ${ }^{14,30}$ Similarly, Lamfon et $\mathrm{al}^{12}$ investigated the in vitro composition of denture biofilms and the susceptibility of Candida spp in these biofilms to antifungal agents. Exposure to single agents such as miconazole, fluconazole, or chlorhexidine did not inhibit the growth of Candida spp. Further, this study shows that the surface of the polymer becomes impregnated with $4 \%$ chlorhexidine, presenting a modified surface leading to increased surface unevenness. Other studies have also noted that $2 \%$ to $4 \%$ chlorhexidine solutions negatively affect the hardness and roughness of acrylic resins. ${ }^{32,46}$

Other types of surface analysis should be done to prove a degradation of the surface of the material when subjected to the action of chlorhexidine. However, frequent exposure to disinfection solutions may interfere with the properties of silicone, causing changes in color, hardness, and tear strength. ${ }^{22-25,27-29,31,35}$ The period of contact of the material of the prosthesis with the disinfectant should be controlled so as not to change the texture of the silicone surface, which may also change color stability and the appearance of the prosthesis. ${ }^{4,31,35}$ Additionally, surface irregularities contribute to increasing microbial adhesion.

Considering that the deleterious effects on materials are affected by the concentration and exposure time of conventional solutions, this study was undertaken to test the antimicrobial efficacy of plant-extract solutions. The results of this study corroborate the literature regarding the antibacterial and antifungal potential of the plant extracts $C$ nardus and $H$ canadensis. ${ }^{39,40}$ The effectiveness of $C$ nardus against $S$ aureus was significant, showing a $92.5 \%$ of reduction in the viability of this biofilm. However, the disinfectant solutions, when used alone, were not capable of completely eliminating the mature biofilm on the surface of silicone. Thus, further studies should be conducted on the use of associated cleaning protocols by combining the mechanical and chemical methods to clean dental prostheses effectively. Therefore, according to some recent studies, the optimal disinfecting solution is still a matter of discussion. ${ }^{27-29}$

Denture hygiene methods have been widely tested. 13-16,46 However, with regard to maxillofacial prostheses, most studies have targeted to their effects on the physical and mechanical properties of materials. $22-25,27-29,31,35$ Thus, these data confirm the need for more knowledge about the composition, occurrence, and biofilm formation of maxillofacial polymeric materials, as well as studies to evaluate the antimicrobial action of cleaning protocols on these materials.

\section{CONCLUSIONS}

Within the limitations of this in vitro study, it was concluded that the silicone polymer subjected to cleaning protocols with different disinfectant solutions significantly reduced the viability of $C$ albicans and $S$ aureus biofilms. Washing by hand with water and neutral soap was the most effective protocol against both microorganisms.

\section{REFERENCES}

1. Atay A, Peker K, Günay Y, Ebrinç S, Karayazgan B, Uysal Ö. Assessment of health-related quality of life in Turkish patients with facial prostheses. Health Qual Life Outcomes 2013:11:11.

2. Goiato MC, Pesqueira AA, da Silva CR, Gennari Filho H, dos Santos DM. Patient satisfaction with maxillofacial prosthesis. Literature review. J Plast Reconstr Aesthet Surg 2009;62:175-80.

3. Guiotti AM, Goiato MC, Santos DM. Evaluation of the Shore A hardness of silicone for facial prosthesis as to the effect of storage period and chemical disinfection. J Craniof Surg 2010;21:323-7.

4. Mancuso DN, Goiato MC, Santos DM. Color stability after accelerated aging of two silicones, pigmented or not, for use in facial prostheses. Braz Oral Res 2009:23:144-8.

5. Andres CT, Haug SP, Brown DT, Bernal G. Effects of environmental factors on maxillofacial elastomers: part II: report of survey. J Prosthet Dent 1992;68: 519-22.

6. Bulbulian AH. Maxillofacial prosthetics: evolution and practical application in patient rehabilitation. J Prosthet Dent 1965;15:554-69.

7. Hanson MD, Shipman B, Blomfield JV, Janus CE. Commercial cosmetics and their role in the coloring of facial prostheses. J Prosthet Dent 1983:50:818-20.

8. Polyzois GL. Color stability of facial silicone prosthetic polymers after outdoor weathering. J Prosthet Dent 1999;82:447-50.

9. Yu R, Koran A III, Craig RG. Physical properties of a pigmented silicone maxillofacial material as a function of accelerated aging. J Dent Res 1980;59: 1141-8.

10. Kiat-Amnuay S, Lemon JC, Powers JM. Effect of opacifiers on color stability of pigmented maxillofacial silicone A-2186 subjected to artificial aging. J Prosthodont 2002;11:109-16.

11. Kiat-Amnuay S, Mekayarajjananonth T, Powers JM, Chambers MS, Lemon JC. Interactions of pigments and opacifiers on color stability of MDX4-4210/type A maxillofacial elastomers subjected to artificial aging. J Prosthet Dent 2006;95:249-57.

12. Lamfon H, Al-Karaawi, McCullough M, Porter SR, Pratten J. Composition of in vitro denture plaque biofilms and susceptibility to antifungals. FEMS Microbiol Lett 2005;242:345-51.

13. de Andrade IM, Cruz PC, Silva-Lovato CH, de Souza RF, Souza-Gugelmin MC, Paranhos HFO. Effect of chlorhexidine on denture biofilm accumulation. J Prosthodont 2012;21:2-6.

14. Pellizzaro D, Polyzois G, Machado AL, Giampaolo ET, Sanitá PV, Vergani CE. Effectiveness of mechanical brushing with different denture cleansing agents in reducing in vitro Candida albicans biofilm viability. Braz Dent J 2012;23:547-54.

15. Altieri KT, Sanitá PV, Machado AL, Giampaolo ET, Pavarina AC, Jorge JH, et al. Eradication of a mature methicillin-resistant Staphylococcus aureus (MRSA) biofilm from acrylic surfaces. Braz Dent J 2013;24:487-91. 
16. Andrade MC, Ribeiro AP, Dovigo LN, Brunetti IL, Giampaolo ET, Bagnato VS, et al. Effect of different pre-irradiation times on curcuminmediated photodynamic therapy against planktonic cultures and biofilms of Candida spp. Arch Oral Biol 2013;58:200-10.

17. Bridier A, Briandet R, Thomas V, Dubois-Brissonnet F. Resistance of bacterial biofilms to disinfectants: a review. Biofouling 2011;27:1017-32.

18. Soll DR. Candida biofilms: is adhesion sexy? Curr Biol 2008;18:153-5.

19. Douglas JL. Candida biofilms and their role in infection. Trends Microbiol 2003;11:30-6.

20. Ramage G, Vandewalle K, Wickes BL, López-Ribot JL. Characteristics of biofilm formation by Candida albicans. Rev Iberoam Micol 2001;18:163-70.

21. Paraskevas S, Rosema NA, Versteeg P, Timmerman MF, van der Velden U, van der Weijden GA. The additional effect of a dentifrice on the instant efficacy of toothbrushing: a crossover study. J Periodontol 2007;78:1011-6.

22. Goiato MC, Haddad MF, Sinhoreti MAC, Santos DM, Pesqueira AA Moreno A. Influence of opacifiers on dimensional stability and detail reproduction of maxillofacial silicone elastomer. Biomed Eng Online 2010; 9:85.

23. Goiato MC, Haddad MF, Pesqueira AA, Moreno A, dos Santos DM, Bannwart LC. Effect of chemical disinfection and accelerated aging on color stability of maxillofacial silicone with opacifiers. J Prosthodont 2011;20:566-9.

24. Goiato MC, Pesqueira AA, Moreno A, dos Santos DM, Haddad MF, Bannwart LC. Effects of pigment, disinfection, and accelerated aging on the hardness and deterioration of a facial silicone elastomer. Polym Degrad Stab 2012:97:1577-80.

25. Pesqueira AA, Goiato MC, Santos DM, Haddad MF, Ribeiro PP, Sinhoreti MAC, et al. Effect of disinfection and accelerated aging on color stability of colorless and pigmented facial silicone. J Prosthodont 2011;20: 305-9.

26. Ferreira M, Pereira-Cenci T, Rodrigues de Vasconcelos L, RodriguesGarcia R, Del Bel Cury A. Efficacy of denture cleansers in denture liners contaminated with Candida species. Clin Oral Invest 2009;13:237-42.

27. Eleni PN, Perivoliotis D, Dragatogiannis DA, Krokida MK, Polyzois GL, Charitidis CA, et al. Tensile and microindentation properties of maxillofacial elastomers after different disinfecting procedures. J Mech Behav Biomed Mater 2013;28:147-55

28. Eleni PN, Krokida MK, Polyzois GL, Gettleman L. Effect of different disinfecting procedures on the hardness and color stability of two maxillofacial elastomers over time. J Appl Oral Sci 2013;21:278-83.

29. Eleni PN, Krokida MK, Polyzois GL, Gettleman L. Dynamic mechanical thermal analysis of maxillofacial prosthetic elastomers: the effect of different disinfecting aging procedures. J Craniofac Surg 2014;25:e251-5.

30. Pavarina AC, Pizzolitto AC, Machado AL, Vergani CE, Giampaolo ET. An infection control protocol: effectiveness of immersion solutions to reduce the microbial growth on dental prostheses. J Oral Rehabil 2003;30:532-6.

31. Guiotti AM, Goiato MC, Santos DM. Marginal deterioration of the silicone for facial prosthesis with pigments after effect of storage period and chemica disinfection. J Craniof Surg 2010;21:142-5.

32. Pinto LR, Acosta EJ, Távora FF, Silva PM, Porto VC. Effect of repeated cycles of chemical disinfection on the roughness and hardness of hard reline acrylic resins. Gerodontology 2010;27:147-53.

33. Haddad MF, Goiato MC, dos Santos DM, Pesqueira AA, Moreno A, Pellizzer EP. Influence of pigment and opacifier on dimensional stability and detail reproduction of maxillofacial silicone elastomer. J Craniofac Surg 2011;22:1612-6.

34. Hatamleh MM, Watts DC. Effect of extraoral aging conditions on color stability of maxillofacial silicone elastomer. J Prosthodont 2010;19:536-43.

35. Guiotti AM, Goiato MC, dos Santos DM, Vechiato-Filho AJ, Cunha BG, Paulini MB, et al. A comparison of conventional and plant-extract disinfectant solutions on the hardness and color stability of a maxillofacial elastomer after artificial aging. J Prosthet Dent 2016;115:501-8.

36. Peralta SL, Carvalho PHA, van de Sande FH, Pereira CMP, Piva E, Lund RG. Selfetching dental adhesive containing a natural essential oil: anti-biofouling performance and mechanical properties. Biofouling 2013;29:345-55.

37. Burt S. Essential oils: their antibacterial properties and potential applications in foods-a review. Int J Food Microbiol 2004;94. 223-3.

38. Siriporn P, Mayura S. The effects of herbal essential oils on the ovipositiondeterrent and ovicidal activities of Aedes aeoypti (Linn.), Anopheles dirus (Peyton and Harrison) and Culex quinquefasciatus (Say). Trop Biomed 2012;29: 138-50.

39. Nakahara K, Alzoreky NS, Yoshihashi T, Nguyen HTT, Trakoontivakorn G. Chemical composition and antifungal activity of essential oil from Cymbopogon nardus. JARQ 2003;37:249-52.

40. Douglas JA, Follett JM, Parmenter GA, Sansom CE, Perry NB, Littler RA. Seasonal variation of biomass and bioactive alkaloid content of goldenseal Hydrastis canadensis. Fitoterapia 2010;8:925-8.

41. Wang A, Liu Q, Jing D, Zhou S, Shao L. Biomechanical properties of nano$\mathrm{TiO}_{2}$ addition to a medical silicone elastomer: the effect of artificial ageing. J Prosthet Dent 2014;42:475-83.

42. Ma T, Johnson M. A technique for fabrication of interim midfacial prostheses using maxillofacial silicone elastomer supported by cellulose acetate matrix is described. J Prosthet Dent 1992;68:940-2.

43. Goveas R, Puttipisitchet O, Shrestha B, Thaworanunta S, Srithavaj T. Silicone nasal prosthesis retained by an intranasal stent: a clinical report. J Prosthet Dent 2012;108:129-32.

44. Acharya V, Montgomery PC. A technique to orient a stone cast in the fabrication of a nasal prosthesis. J Prosthet Dent 2014;112:692-4.

45. Pitangui NS, Sardi JC, Silva JF, Benaducci T, Moraes da Silva RA, RodríguezArellanes G, et al. Adhesion of Histoplasma capsulatum to pneumocytes and biofilm formation on an abiotic surface. Biofouling 2012;28:711-8.

46. Silva FC, Kimpara ET, Mancini MN, Balducci I, Jorge AO, Koga-Ito CY. Effectiveness of six different disinfectants on removing five microbial species and effects on the topographic characteristics of acrylic resin. J Prosthodont 2008; 17:627-33

\section{Corresponding author:}

Dr Aimée Maria Guiotti

Department of Dental Materials and Prosthodontics

Araçatuba Dental School, São Paulo State University (UNESP)

José Bonifácio, 1153, Araçatuba

São Paulo16015-050

BRAZIL

Email: aimee@foa.unesp.br

Copyright (C) 2016 by the Editorial Council for The Journal of Prosthetic Dentistry. 